\title{
Coping with Negative Workplace Gossip: The Joint Roles of Self-Monitoring and Impression Management Tactics
}

\author{
Jun Xie \\ Center for Cantonese Merchants Research \\ Guangdong University of Foreign Studies \\ Guangzhou, China \\ Tel: +86 Tel: 86-135-60087462 \\ Email:xiejun3874@163.com
}

\section{Qihai Huang}

Keel University Management School

Staffordshire, ST5 5BG, UK

Tel: +44 (0)1524 510883

Email:Q.Huang@,Keele.ac.uk

Hongli Wang (Corresponding author)

School of Business Administration

South China University of Technology

Guangzhou, China

Tel: +86 Tel: 86-186-20833359 


\title{
Minghao Shen
}

\author{
Center for Cantonese Merchants Research \\ Guangdong University of Foreign Studies \\ Guangzhou, China
}

Tel: +86 Tel: 86-135-60418288

Email:215726723@qq.com

\begin{abstract}
Author notes
Jun Xie is Associate Professor at Center for Cantonese Merchants Research, Guangdong University of Foreign Studies, Guangzhou, China. His current research interests are leadership, interpersonal mistreatment and voice behavior.
\end{abstract}

Qihai Huang is Professor at Keel University, UK. His current research interests are organizational behavior, entrepreneur and creativity.

Hongli Wang is Associate Professor at Faculty of Business Management, South China University of Technology, Guangzhou, China. Her current research interests are emotion, trust and organizational behavior.

Minghao Shen is Professor at Center for Cantonese Merchants Research, Guangdong University of Foreign Studies, Guangzhou, China. His current research interests are industry competitiveness and business model innovation. 
Conflict of Interest: Jun Xie has received research grants from National Natural Science foundation of China (71502042); Corresponding Author Hongli Wang has received research grants from National Natural Science foundation of China (71402057).

\title{
Coping with Negative Workplace Gossip: The Joint Roles of Self- Monitoring and Impression Management Tactics
}

\begin{abstract}
Although researchers have examined the effects of negative workplace gossip on target employees' work-related behavior, it remains unclear when and how personality traits play a role between negative workplace gossip and organizational citizenship behavior (OCB). Drawing upon the transactional model of stress and coping, we posit a mediated moderation model of the effects of self-monitoring and impression management tactics on the relationship between negative workplace gossip and target employees' OCB. By collecting supervisor-subordinate dyadic time-lagged data, we demonstrated that the relationship between negative workplace gossip and OCB was weaker when employees were high self-monitors. In addition, we found that the moderating effects of selfmonitoring were mediated by the use of impression management tactics.
\end{abstract}

Keywords: Negative workplace gossip; Self-monitoring; Impression management tactics; Organizational citizenship behavior; 


\section{Introduction}

Negative workplace gossip is defined as the informal and negative evaluative discussion or the spreading of rumors about another member within the organization who is not present (e.g., discussing a colleague's poor performance) (Kurland \& Pelled, 2000; Chandra \& Robinson, 2009). As a highly salient stressor, negative gossip may hurt the target's image and reputation (Michelson, Van Iterson, \& Waddington, 2010), cause emotional exhaustion (Liu, Kwan, \& Zhang, 2018) and increase employee turnover intentions (Emler, 1994).

As negative gossip is often covert and indirect, it is difficult to find the original gossiper, verify its content or prevent the spread of gossip (Foster, 2004). The target employee's response to negative gossip is also likely to be less direct or expressive. For example, they may withhold organizational citizenship behavior (OCB), defined as "individual behavior that is discretionary, not directly or explicitly recognized by the formal reward system" (Organ, 1988, p. 4). In accordance with this logic, some scholars have proved that negative gossip has a detrimental effect on the target's OCB $(\mathrm{Wu}$, Birtch, Chiang, \& Zhang, 2018). However, researchers have also shown that the target of negative gossip may constrain selfish behavior and increase cooperative and helpful behavior under certain circumstances (Kniffin \& Sloan, 2010; Feinberg, Willer, \& Schultz, 2014). Thus, there is little consensus on the relationship between negative gossip and the target's OCB, which suggests the existence of moderators to explain why different individuals react differently to negative gossip. 
To fill the research gap, we draw on the transactional model of stress and coping (TMSC; Lazarus \& Folkman, 1987) to theorize that personality traits will influence the target's appraisal of negative gossip, leading to the adaptation of different coping strategies to eliminate or reduce the detrimental impact of such a threatening stressor. Self-monitoring, a dispositional tendency to regulate and control the public appearance of one's self (Furnham \& Capon, 1983; Snyder, 1987), is a key dispositional attribute that governs one's reactions to negative gossip. The literature related to personality and stress suggests that individuals who are high self-monitors are more concerned about their standing within stressful environments and tend to regulate their expressive behavior for the sake of public appearance (Fuglestad \& Snyder, 2009). We thus focus on the moderating role that self-monitoring plays in the association between negative gossip and OCB.

Furthermore, just as McCrae and Costa (1996) posited, the impact of personality trait on individual behavior is realized through its influence on the extent to which individuals adapt to the environment. One category of adaptations to the environment is the coping strategies that can be taken to deal with stressors (Connor-Smith \& Flachsbart, 2007). Impression management tactics, defined as the process by which people attempt to influence the image others to have of them (Rosenfeld, Giacalone, \& Riordan, 1995), is an active coping strategy in the context of negative gossip.

Accordingly, we propose that the detrimental effects of negative gossip on OCB will be (a) weaker for employees high in self-monitoring, (b) weaker for employees who implement impression management tactics. Additionally, because individuals high 
in self-monitoring are more likely to adopt active coping actions (Scott, Barnes, \& Wagner, 2012), we ultimately hypothesize that the moderating effect of self-monitoring will be mediated through its effects on impression management tactics. Our hypothesized mediated moderation model is presented in Figure 1.

---Insert Figure 1 here---

\section{Theoretical framework}

2.1. The moderating role of self-monitoring

According to TMSC (Lazarus \& Folkman, 1987), after evaluating the potential impact of a given stressor (primary appraisal stage), individuals will determine what should be done to deal with the stressor (secondary appraisal stage). Decisions about how to deal with such stress may vary widely across individuals. Extending this line of logic, we propose that higher self-monitoring will weaken the adverse impact of negative gossip on OCB.

Employees who are the target of negative gossip may shift extra-role efforts to deal with the gossip thereby reducing their OCB. However, extant research suggests that high self-monitors are more likely to respond to stressors in productive ways than low self-monitors (Allen, Weeks, \& Moffitt, 2005). This is because individuals high in self-monitoring have a strong motivation to project a positive image and have a strong competency to adjust their behavior under stressful conditions (Snyder, 1987). When perceiving to be the target of negative gossip, employees high in self-monitoring are more likely to maintain or even increase their OCB in order to avoid further damage of 
their public appearance or counteract the destroyed reputation. Accordingly, their OCB will be less adversely affected by negative gossip. In contrast, individuals who are low in self-monitoring attach a lower psychological motivation to image enhancement in social situations and are less effective at regulating their behavior according to the stressful environment (Scott et al., 2012). Therefore, they are more likely to exhibit decreased $\mathrm{OCB}$ when perceiving to be the target of negative gossip. Thus, we hypothesize:

Hypothesis 1. Self-monitoring moderates the relationship between negative workplace gossip and OCB such that the relationship is negative for those low in self-monitoring but not for those high in self-monitoring.

2.2. The role of impression management tactics

To shed light on the process through which self-monitoring's moderating effect occurs, we propose that impression management tactics will mediate the moderating effect of self-monitoring on the relationship between negative workplace gossip and OCB. As depicted in Figure 1, in our mediated moderation model, impression management tactics, driven by self-monitoring, mitigate the effect of negative gossip on OCB. We first explain why self-monitoring leads to impression management tactics and then why impression management tactics weaken the detrimental impact of negative gossip on OCB.

TMSC suggests that, in the secondary appraisal stage, individuals will determine which coping strategies are most appropriate for the stressful situation (Lazarus \& 
Folkman, 1987). Personality may affect coping strategy selection directly by constraining or facilitating the use of specific strategies (Bolger \& Zuckerman, 1995; Carver \& Connor-Smith, 2010). We propose two reasons why high self-monitoring employees tend to perform impression management tactics.

First, high self-monitors tend to have different attitudes, perspectives, and behaviors to suit different social situations until they are satisfied with the image they have conveyed to others (Snyder, 1987). At its core, self-monitoring "relates to statusoriented impression management motives" (Gangestad \& Snyder, 2000, p. 547). In the context of negative gossip, an employee high in self-monitoring will be more sensitive to cues calling for the need to manage their image compared to low self-monitors. Second, self-monitoring is positively associated with skills concerning social awareness and self-presentation (Scott et al., 2012; Parks-Leduc et al., 2014). Thus, high selfmonitors are more likely to use impression management tactics and use such tactics more effectively (Turnley \& Bolino, 2001). In contrast, low self-monitors do not have adequate social or presentation skills to perform impression management tactics properly in the workplace. Thus, we hypothesize:

Hypothesis 2a. Self-monitoring is positively related to impression management tactics.

We further propose that impression management tactics relieve the detrimental effect of negative gossip on OCB. As TMSC indicates (Lazarus \& Folkman, 1987), the amount and nature of resources available to individuals influence their coping effectiveness in a stressful environment. Specifically, through impression management, 
target employees can construct a positive image in the eyes of supervisor or coworkers, promote favorable social interactions (Harvey et al., 2007), and gain instrumental and social support from others (Huang et al., 2013). Such social interactions and support gained will buffer the stress experienced by target employees, thus mitigate the adverse impact of negative gossip on OCB. Prior studies have suggested that social resources facilitated by social interactions may depress or prevent a negative appraisal response, thus buffer the impact of workplace negative stressors on outcomes (Cohen \& Wills, 1985; Wu et al., 2012). Moreover, by engaging in active coping action under stressful conditions, individuals can feel more efficacious and acquire a sense of control, which also may reduce the stress reaction to stressors (Carver \& Connor-Smith, 2010; Huang et al., 2013). In the context of negative gossip, one way to do so is by engaging in impression management tactics. Recent research has shown that individuals who adopt active coping strategies are more likely to regulate their behavioral and emotional responses to workplace stressor (Nandkeolyar et al., 2014). Thus, we hypothesize:

Hypothesis 2b. Impression management tactics moderates the relationship between negative workplace gossip and OCB such that the relationship between negative gossip and OCB is weaker for individuals who engage in impression management tactics.

According to Grant and Berry (2011), a mediated moderation model is a kind of research in which a moderating variable (self-monitoring) weakens the relationship between the independent (negative gossip) and dependent variables (OCB); the moderator (self-monitoring) drives the mediating variable (impression management 
tactics); and the mediating variable also has a moderating effect on the relationship between the independent (negative gossip) and dependent variables (OCB). The end result of this process is that the original moderating effect of self-monitoring is mediated through its effect on impression management tactics. Thus, we hypothesize:

Hypothesis 2c: Impression management tactics would mediate the moderating effects of self-monitoring on the relationship between negative workplace gossip and OCB.

\section{Methods}

\subsection{Procedure and participants}

The study was reviewed and approved by the Ethics Committee. To test our hypotheses, we conducted a two-wave survey in 5 large companies located in southern China. Specifically, in the first-wave of survey (Time 1), employees were asked to report perceived negative workplace gossip, self-monitoring, impression management tactics, and demographic information (i.e., age, gender, education, and organizational tenure). One month later (Time 2), supervisors (only those whose subordinates had returned completed surveys in Time 1) were asked to rate their subordinates' OCB.

With the assistance of the HR manager we randomly selected 448 subordinates and their corresponding 448 supervisors from the participating companies. At the first stage (Time 1), we sent questionnaires to the 448 employees and 353 completed questionnaires were returned, yielding a response rate of $78 \%$. At the second stage (Time 2), we sent 353 questionnaires to the corresponding supervisors and 293 supervisors returned the ratings of their subordinates' OCB, yielding a response rate of 
$83 \%$. Matching the subordinate and supervisor responses yielded a total of 275 dyads. In terms of their demographic profile, subordinates were on average 33.61 years of age $(\mathrm{SD}=6.84)$, male $(54.2 \%)$, and employed for an average of 4.62 years in their respective organization $(\mathrm{SD}=3.84)$.

\subsection{Measures}

All variables were measured on a five-point Likert-type scales, ranging from 1 (strongly disagree) to 5 (strongly agree) unless otherwise specified.

\subsubsection{Negative Workplace Gossip}

Negative workplace gossip was measured using the three-item scale used by $\mathrm{Wu}$ et al. (2018). Responses were made on a scale ranging from 1 (never) to 5 (daily). A sample item is: "In the past six months, others (e.g., coworkers and/or supervisors) communicated damaging information about me in the workplace". Cronbach's alpha for this scale in this study was .82 .

\subsubsection{Self-Monitoring}

Self-monitoring was measured with the eight positively worded items on the scale developed by Snyder and Gangestad (1986). A sample item is: "In different situations and with different people, I often act like a very different person". Cronbach's alpha for this scale in this study was .89 .

\subsubsection{Impression Management Tactics}

Impression management tactics were measured with twelve items adapted from Wayne and Ferris (1990). A sample item is: "present myself to others as being a friendly 
person". Cronbach's alpha for this scale in this study was .92 .

\subsubsection{Organizational Citizenship Behavior}

Organizational citizenship behavior was measured with the ten-item scale used by Farh, Earley, and Lin (1997). A sample item is: "willingly give time to help unit members who have work-related problems". Cronbach's alpha for this scale in this study was .88 .

\subsubsection{Control variables}

Following prior negative workplace gossip, we controlled for gender, age, education, and organizational tenure. As our data was collected from five companies, we created four dummy-coded variables and entered these terms in our analyses.

\section{Results}

\subsection{Confirmatory factor analysis}

We conducted a confirmatory factor analysis (CFA) to evaluate the discriminant validity of the four key variables. The indices and changes in Chi-square suggest that the four-factor model $\left(\chi^{2}[489]=1302.89, \mathrm{RMSEA}=.078, \mathrm{SRMR}=.065, \mathrm{CFI}=.93\right.$, $\mathrm{TLI}=.93$ ) yielded a better fit than the other models, indicating that these constructs are empirically distinct.

\subsection{Descriptive statistics and correlations}

Table 1 shows the means, standard deviations, and inter-correlations associated with our variables.

---Insert Table 1 here--- 


\subsection{Hypotheses testing}

To test hypothesis 1, we first entered the control variables (gender, age, education, organizational tenure, and companies) (Model 3 in Table 2), and then the main effect of negative workplace gossip (Model 4) followed by the two-way interaction of negative workplace gossip and self-monitoring (Model 5). The results from Model 4 (see Table 2) show that after the control variables are taken into account negative workplace gossip is negatively related to $\mathrm{OCB}(\beta=-.24, p<.001)$. As shown in Model 5 the interaction term for negative workplace gossip and self-monitoring is positive and significant ( $\beta$ $=.13, p<.05)$.

---Insert Table 2---

We plotted the interaction in order to interpret the interaction term (Aiken \& West, 1991). The pattern of the results is consistent with our prediction and is shown in Figure 2. The simple slopes analysis shows that the effect of negative gossip on OCB is nonsignificant when self-monitoring is one standard deviation above the mean ( $\beta=-.07$, $p>.05)$ and is negative and significant when self-monitoring is one standard deviation below the mean $(\beta=-.22, p<.001)$. These results are consistent with Hypothesis 1 . ---Insert Figure 2 here---

As indicated in Table 2, to test Hypothesis $2 \mathrm{a}$ we first entered the control variables (Model 1) and then entered the main effect of self-monitoring (Model 2). The results from Model 2 (see Table 2) show that, after considering the controlled demographics variables, self-monitoring is positively related to impression management tactics ( $\beta$ 
$=.33, p<.001)$. Hence, Hypothesis $2 \mathrm{a}$ is supported.

Model 6 in Table 2 shows that the interaction between negative workplace gossip and impression management tactics is significant $(\beta=.22, p<.001)$. The simple slopes analysis shows that the relationship between negative gossip and OCB is negative and significant when impression management tactics are one standard deviation below the mean ( $\beta=-.23, p<.001)$ and is non-significant when impression management tactics are one standard deviation above the mean $(\beta=.01, p>.05)$. The plot of the interaction between negative workplace gossip and impression management tactics is shown in Figure 3. These results are consistent with Hypothesis $2 b$.

---Insert Figure 3 here---

The results in Table 2 indicate that the regression coefficient for the interaction between negative gossip and impression management tactics is significant ( $\beta=.22, p$ $<.001$ ) in our model, whereas the regression coefficient for the interaction between negative workplace gossip and self-monitoring is non-significant ( $\beta=.08, p>.05$ ) This suggests that the moderating effects of self-monitoring on the relationship between negative gossip and OCB are fully mediated by impression management tactics.

To further test Hypothesis 2c, we applied the analytical procedures recommended by Grant and Berry (2011). Specifically, our previous analyses showed that selfmonitoring predicted impression management tactics and that impression management tactics moderated the association between negative gossip and $\mathrm{OCB}$, which reduced the coefficient for the moderating effect of self-monitoring. To examine the size of the indirect effect of self-monitoring (in moderating the relationship between negative 
gossip and OCB) through the mediator of impression management tactics, we used a bootstrapping procedure. We constructed bias-corrected confidence intervals by drawing 2,000 random samples with replacement from the full sample. An indirect effect is significant when the $95 \%$ confidence interval excludes zero (Edwards \& Lambert, 2007). In our data, the size of the indirect effect from the full sample was .07 and the $95 \%$ confidence interval from the bootstrap analysis excluded zero [.024, .123]. These results support Hypothesis $2 \mathrm{c}$ again, demonstrating that impression management tactics mediated the moderating effect of self-monitoring on the relationship between negative gossip and OCB. We used the information from Table 2 to compute estimates of the direct, indirect, and total effects of our model. These estimates are shown in Table 3. Specifically, as shown in Table 3, the direct effect of the interaction between negative gossip and self-monitoring on OCB is .13, the indirect effect of impression management tactics is .07 and the total effect is .20 .

---Insert Table 3---

\section{Discussion}

\subsection{Theoretical implications}

This study attempted to contribute to workplace gossip research by exploring when and how self-monitoring reduces the impact of negative gossip on OCB. This study makes several contributions to the literature. First, we expanded the research on workplace gossip by finding that self-monitoring can moderate the relationship between negative workplace gossip and OCB. Although the inconsistent findings linking negative gossip to proactive behavior point to the potential presence of moderators, 
little attention has been paid to how individuals respond differently to negative workplace gossip (Wu et al., 2018). Such omission has restricted the understanding of whether personality traits might mitigate or exacerbate the effect of negative gossip (Foster, 2004). Based on the TMSC (Lazarus \& Folkman, 1987), we filled the gap by demonstrating that the relationship between negative gossip and OCB is negative for low self-monitors but not for high self-monitors. This finding contributes to workplace gossip literature by delineating the role of self-monitoring in coping with negative gossip such that self-monitoring can mitigate one's behavioral response to negative gossip. Moreover, by extending this theoretical implication, our findings show the possibility that personality traits such as self-monitoring may mitigate the adverse effect, not only from negative gossip but also from other workplace stressors such as workplace ostracism (Ferris et al., 2008). Hence, self-monitoring can be an important moderator for broadening the existing research on work stress (Bowling \& Beehr, 2006).

Second, our study makes a contribution to gossip and impression management literature by demonstrating that those impression management tactics serve as a coping strategy that reduces the detrimental impact of negative gossip. Although several studies suggest that negative gossip might damage the target's reputation and public appearance (Foster, 2004; Michelson et al., 2010), little attention has been paid to the coping strategies that the target adopts. Our study directly examined whether impression management tactics can limit the adverse effects of negative gossip. Indeed, we found that for target employees who adopt impression management tactics the negative relationship between negative gossip and OCB is weaker. This finding 
supports the notion that coping strategies play an important role in alleviating victimization (Aquino \& Bradfield, 2000; Wu et al., 2012). Therefore, our study responds to the call for further exploration of factors that determine people's response to the gossip (Foster, 2004).

Third, this study contributes to personality and coping research by demonstrating that impression management tactics, which are influenced by self-monitoring, may subsequently determine individuals' responses to negative workplace gossip. Whereas prior studies have examined the role of individuals' personality traits and coping independently when responding to workplace stressors (Carver \& Connor-Smith, 2010), this study investigates the interaction of personality and coping in the context of negative gossip. Our findings show that impression management tactics serve as mediating mechanisms which account for the moderating effects of self-monitoring on the relationship between negative gossip and OCB. In so doing, we shed light on how personality and coping strategies exert their influence in the relationship between negative gossip and OCB.

\subsection{Practical implications}

First, our results indicate that negative gossip may render more negative effects on low self-monitoring individuals. By identifying these target employees and providing them with appropriate training and counseling, managers can help these employees alleviate the advert effects of negative gossip. For example, managers should communicate regularly and consistently with the target employees. Consistent and authentic communication will reduce the psychological distress caused by negative 
gossip.

Second, our results imply that high self-monitors are more likely to use impression management tactics. Target employees who adopt impression management tactics are more likely to regulate their behavioral and emotional responses to negative gossip, thereby mitigating its negative influence on OCB. Therefore, for those target employees, impression management tactics may be one of the effective coping strategies for negative gossip. However, past research has also suggested that impression management may even make the situation worse, especially for those who do not have an adequate level of ability to perform it properly in the workplace (Turnley \& Bolino, 2001; $\mathrm{Wu}$ et al., 2012). Thus, although our results indicated that impression management can be useful for coping with negative gossip, such tactics should be tempered given that the effectiveness of impression management may be constrained by contexts.

\subsection{Limitations and future directions}

The present study inevitably has weaknesses. First, although our time-lagged research design enables stronger causal inferences than the cross-sectional design, we cannot unequivocally say that the direction of causality is determined. Future research could better rule out the possibility of a reverse relationship between negative gossip and OCB by using a longitudinal research design. Second, although this study focuses on the moderating role of self-monitoring, it is possible that other personality traits (e.g., proactive personality), may moderate the relationship between negative gossip and work-related behaviors. The next important step for workplace gossip research is, 
therefore, to explore the moderating role of other personality traits from different theoretical perspectives. Finally, this study does not explore the mediating mechanism of how perceived negative gossip affects OCB. The next important step for workplace gossip research is, therefore, to explore the role of the potential mediators.

\section{Conclusion}

Based on the TMSC, our research suggests that self-monitoring, as a key moderator, can buffer the relationship between negative gossip and OCB. Additionally, impression management tactics, as an important mediator, explains how selfmonitoring buffers the aforementioned relationship via the implementation of effective coping strategies.

\section{References}

Aquino, K., \& Bradfield, M. (2000). Perceived victimization in the workplace: The role of situational factors and victim characteristics. Organization Science, 11(5), 525537.

Allen, D. G., Weeks, K. P., \& Moffitt, K. R. (2005). Turnover intentions and voluntary turnover: the moderating roles of self-monitoring, locus of control, proactive personality, and risk aversion. Journal of Applied Psychology, 90(5), 980-990.

Aiken, L. S., West, S. G., \& Reno, R. R. (1991). Multiple regression: Testing and interpreting interactions. Newbury Park: Sage.

Bolger, N., \& Zuckerman, A. (1995). A framework for studying personality in the stress process. Journal of Personality and Social Psychology, 69(5), 890-902.

Bowling, N. A., \& Beehr, T. A. (2006). Workplace harassment from the victim's perspective: A theoretical model and meta-analysis. Journal of Applied Psychology, 91(5): 998-1012.

Carver, C. S., \& Connor-Smith, J. (2010). Personality and coping. Annual Review of Psychology, 61, 679-704.

Chandra, G., \& Robinson, S. L. (2009). They're talking about me again: The impact of being the target of gossip on emotional distress and withdrawal. In Academy of 
Management Conference. Chicago.

Connor-Smith, J. K., \& Flachsbart, C. (2007). Relations between personality and coping: a meta-analysis. Journal of personality and social psychology, 93(6), 1080-1107.

Edwards, J. R., \& Lambert, L. S. (2007). Methods for integrating moderation and mediation: a general analytical framework using moderated path analysis. Psychological Methods, 12(1), 1-22.

Emler, N. (1994). Gossip, reputation and social adaptation. In R. F. Goodman \& A. BenZe'ev (Eds.), Good gossip (pp. 119-140). Lawrence, KS: University of Kansas Press.

Farh, J. L., Earley, P. C., \& Lin, S. C. (1997). Impetus for action: A cultural analysis of justice and organizational citizenship behavior in Chinese society. Administrative Science Quarterly, 42(3), 421-444.

Feinberg, M., Willer, R., \& Schultz, M. (2014). Gossip and ostracism promote cooperation in groups. Psychological Science, 25(3), 656-664.

Ferris, D. L., Brown, D. J., Berry, J. W., \& Lian, H. (2008). The development and validation of the Workplace Ostracism Scale. Journal of Applied Psychology, 93(6), 1348-1366.

Foster, E. K. (2004). Research on gossip: Taxonomy, methods, and future directions. Review of General Psychology, 8(2), 78-99.

Furnham, A., \& Capon, M. (1983). Social skills and self-monitoring processes. Personality and Individual Differences, 4(2), 171-178.

Grant, A. M., \& Berry, J. W. (2011). The necessity of others is the mother of invention: Intrinsic and prosocial motivations, perspective taking, and creativity. Academy of Management Journal, 54(1), 73-96.

Harvey, P., Stoner, J., Hochwarter, W., \& Kacmar, C. (2007). Coping with abusive supervision: The neutralizing effects of ingratiation and positive affect on negative employee outcomes. The Leadership Quarterly, 18(3), 264-280.

Huang, G. H., Zhao, H. H., Niu, X. Y., Ashford, S. J., \& Lee, C. (2013). Reducing job insecurity and increasing performance ratings: Does impression management matter? Journal of Applied Psychology, 98(5), 852-862.

Kniffin, K. M., \& Sloan Wilson, D. (2010). Evolutionary perspectives on workplace gossip: Why and how gossip can serve groups. Group \& Organization Management, 35(2), 150-176.

Kurland, N. B., \& Pelled, L. H. (2000). Passing the word: Toward a model of gossip and power in the workplace. Academy of Management Review, 25(2), 428-438.

Lazarus, R. S. and Folkman, S. (1987), Transactional theory and research on emotions and coping, European Journal of Personality, 1, 141-169.

Liu, X. Y., Kwan, H. K., \& Zhang, X. (2018). Introverts maintain creativity: A resource depletion model of negative workplace gossip. Asia Pacific Journal of Management, $1-20$.

McCrae, R. R., and Costa, P. T. (1996). Toward a new generation of personality theories: Theoretical contexts for the five-factor model. In J. S. Wiggins (Ed.), The five- 
factor model of personality: Theoretical perspectives (pp. 51-87). New York, NY: Guilford Press.

Michelson, G., Van Iterson, A., \& Waddington, K. (2010). Gossip in organizations: Contexts, consequences, and controversies. Group \& Organization Management, 35(4), 371-390.

Nandkeolyar, A. K., Shaffer, J. A., Li, A., Ekkirala, S., \& Bagger, J. (2014). Surviving an abusive supervisor: The joint roles of conscientiousness and coping strategies. Journal of Applied Psychology, 99(1), 138-150.

Organ, D. W. 1988. Organizational citizenship behavior: The good soldier syndrome. Lexington, MA: Lexington Books.

Parks-Leduc, L., Pattie, M. W., Pargas, F., \& Eliason, R. G. (2014). Self-monitoring as an aggregate construct: relationships with personality and values. Personality and Individual Differences, 58, 3-8.

Rosenfeld, P., Giacalone, R. A., \& Riordan, C. A. (1995). Impression management in organizations: Theory, measurement, practice. Van Nostrand Reinhold.

Scott, B. A., Barnes, C. M., \& Wagner, D. T. (2012). Chameleonic or consistent? A multilevel investigation of emotional labor variability and selfmonitoring. Academy of Management Journal,55(4), 905-926.

Snyder, M. (1987). Public appearances, private realities: The psychology of selfmonitoring. WH Freeman/Times Books/Henry Holt \& Co.

Turnley, W. H., \& Bolino, M. C. (2001). Achieving desired images while avoiding undesired images: exploring the role of self-monitoring in impression management. Journal of Applied Psychology, 86(2), 351-360.

Wayne, S. J., \& Ferris, G. R. (1990). Influence tactics, affect, and exchange quality in supervisor-subordinate interactions: A laboratory experiment and field study. Journal of Applied Psychology, 75(5), 487-499.

Wu, L. Z., Yim, F. H. K., Kwan, H. K., \& Zhang, X. (2012). Coping with workplace ostracism: The roles of ingratiation and political skill in employee psychological distress. Journal of Management Studies, 49(1), 178-199.

Wu, L. Z., Birtch, T. A., Chiang, F. F., \& Zhang, H. (2018). Perceptions of negative workplace gossip: A self-consistency theory framework, Journal of Management, 44(5), 1873-1898. 


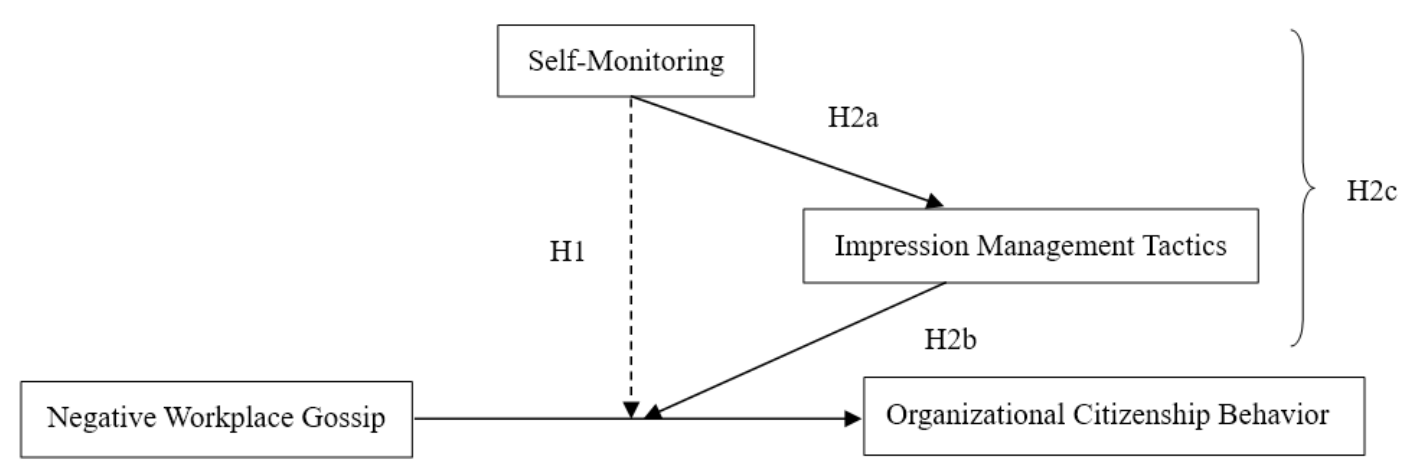

Figure 1. Hypothesized model. $\mathrm{H}=$ Hypothesis . 


\section{Table 1}

Means, standard deviations, and correlations

\begin{tabular}{|c|c|c|c|c|c|c|c|c|c|c|}
\hline Variable & M & $\mathrm{SD}$ & 1 & 2 & 3 & 4 & 5 & 6 & 7 & 8 \\
\hline 1. Gender ${ }^{a}$ & .54 & .50 & - & & & & & & & \\
\hline 2. $\mathrm{Age}^{\mathrm{b}}$ & 33.61 & 6.84 & -.05 & - & & & & & & \\
\hline 3. Education ${ }^{\mathrm{c}}$ & 2.91 & .56 & -.03 & $-.16^{* *}$ & - & & & & & \\
\hline 4. Tenure ${ }^{d}$ & 4.62 & 3.84 & -.04 & $.72^{* * * *}$ & $-.20^{* * *}$ & - & & & & \\
\hline 5. NWG & 2.24 & .78 & .07 & .02 & -.09 & 0 & $(.82)$ & & & \\
\hline 6. SM & 3.23 & .80 & -.06 & .06 & .09 & .11 & -.05 & (.89) & & \\
\hline 7. IMT & 2.72 & .77 & .07 & -.10 & -.06 & -.07 & $.31^{* * * *}$ & $.29^{* * * *}$ & $(.92)$ & \\
\hline 8. OCB & 3.30 & .58 & -.06 & -.02 & .09 & -.12 & $-.23^{* * * *}$ & $.14^{*}$ & $-.13^{*}$ & $(.88)$ \\
\hline
\end{tabular}

Note. Cronbach's alpha coefficients are shown in boldface on the diagonal. NWG = negative workplace gossip, SM $=$ self-monitoring, $\mathrm{IMT}=$ impression management tactics, $\mathrm{OCB}=$ organizational citizenship behavior.

a $1=$ male, $0=$ female.

$\mathrm{b}$ in years.

${ }^{\mathrm{c}} 1$ = high school or below, 2 = junior college, 3 = bachelor's degree, 4 = master's degree, $5=$ doctoral degree.

$\mathrm{d}$ in years

${ }^{*} \mathrm{p}<.05,{ }^{* *} \mathrm{p}<.01,{ }^{* * *} \mathrm{p}<.001$. 
Table 2

Regression Analyses ${ }^{a}$

\begin{tabular}{|c|c|c|c|c|c|c|}
\hline \multirow{2}{*}{ Variable } & \multicolumn{3}{|c|}{ IMT } & \multicolumn{2}{|c|}{ OCB } & \multirow[b]{2}{*}{ Model 6} \\
\hline & Model 1 & Model 2 & Model 3 & Model 4 & Model 5 & \\
\hline Company 1 & .03 & -.002 & $-.16^{*}$ & $-.18^{*}$ & $-.16^{*}$ & $-.15^{*}$ \\
\hline Company 2 & .14 & $.15^{*}$ & .02 & .01 & .02 & .06 \\
\hline Company 3 & -.02 & -.01 & -.02 & .004 & .02 & .03 \\
\hline Company 4 & -.04 & -.06 & -.11 & -.12 & -.12 & $-.14^{*}$ \\
\hline Gender & .06 & .08 & -.06 & -.05 & -.04 & -.01 \\
\hline Age & -.05 & -.03 & .17 & $.17^{*}$ & .16 & $.17^{*}$ \\
\hline Education & -.09 & $-.12^{*}$ & .07 & .06 & .05 & .03 \\
\hline Tenure & -.04 & -.09 & $-.23^{* *}$ & $-.24^{* * *}$ & $-.21^{* *}$ & $-.22^{* * *}$ \\
\hline $\mathrm{SM}$ & & $.33^{* * * *}$ & $.17^{* * *}$ & $.16^{* * *}$ & $.16^{* * *}$ & $.20^{* * * *}$ \\
\hline NWG & & & & $-.24^{* * * *}$ & $-.21^{* * * *}$ & $-.17^{* * * *}$ \\
\hline $\mathrm{NWG} \times \mathrm{SM}$ & & & & & $.13^{*}$ & .08 \\
\hline IMT & & & & & & $-.21^{* * *}$ \\
\hline $\mathrm{NWG} \times \mathrm{IMT}$ & & & & & & $.22^{* * * *}$ \\
\hline $\mathrm{R}^{2}$ & .04 & .15 & .08 & .14 & .15 & .21 \\
\hline$\triangle \mathrm{R}^{2}$ & & $.11^{* * * *}$ & & $.06^{* * * *}$ & $.01^{*}$ & $.06^{* * * *}$ \\
\hline $\mathrm{F}$ & 1.41 & $5.01^{* * * *}$ & $2.65^{* * *}$ & $4.24^{* * *}$ & $4.33^{* * * *}$ & $5.37^{* * * *}$ \\
\hline
\end{tabular}

a Values in bold are relevant to tests of hypotheses. NWG = negative workplace gossip, SM = self-monitoring, IMT

= impression management tactics, $\mathrm{OCB}=$ organizational citizenship behavior

${ }^{*} \mathrm{p}<.05 .^{* *} \mathrm{p}<.01 .^{* * * *} \mathrm{p}<.001$.

Table 3 
Direct, indirect, and total effects of our model

\begin{tabular}{ccccc}
\hline & & DE & IE & Total effects \\
\hline $\mathrm{P}_{\mathrm{ZM}}$ & $\mathrm{P}_{\mathrm{XM}}$ & $\mathrm{P}_{\mathrm{XZ}}$ & $\mathrm{P}_{\mathrm{ZM}} \mathrm{P}_{\mathrm{XM}}$ & $\mathrm{P}_{\mathrm{XZ}}+\mathrm{P}_{\mathrm{ZM}} \mathrm{P}_{\mathrm{XM}}$ \\
.33 & .22 & .13 & .07 & .20 \\
\hline
\end{tabular}

Note. DE refers to the direct effect of the interaction between negative gossip and self-monitoring on OCB. IE refers to the indirect effect of impression management tactics. $\mathrm{P}_{\mathrm{ZM}}$ represents the path from self-monitoring to impression management tactics. Рхм represents the regression coefficient for the interaction between negative gossip and impression management tactics. $\mathrm{PXz}_{\mathrm{Xz}}$ represents the regression coefficient for the interaction between negative gossip and self-monitoring. 


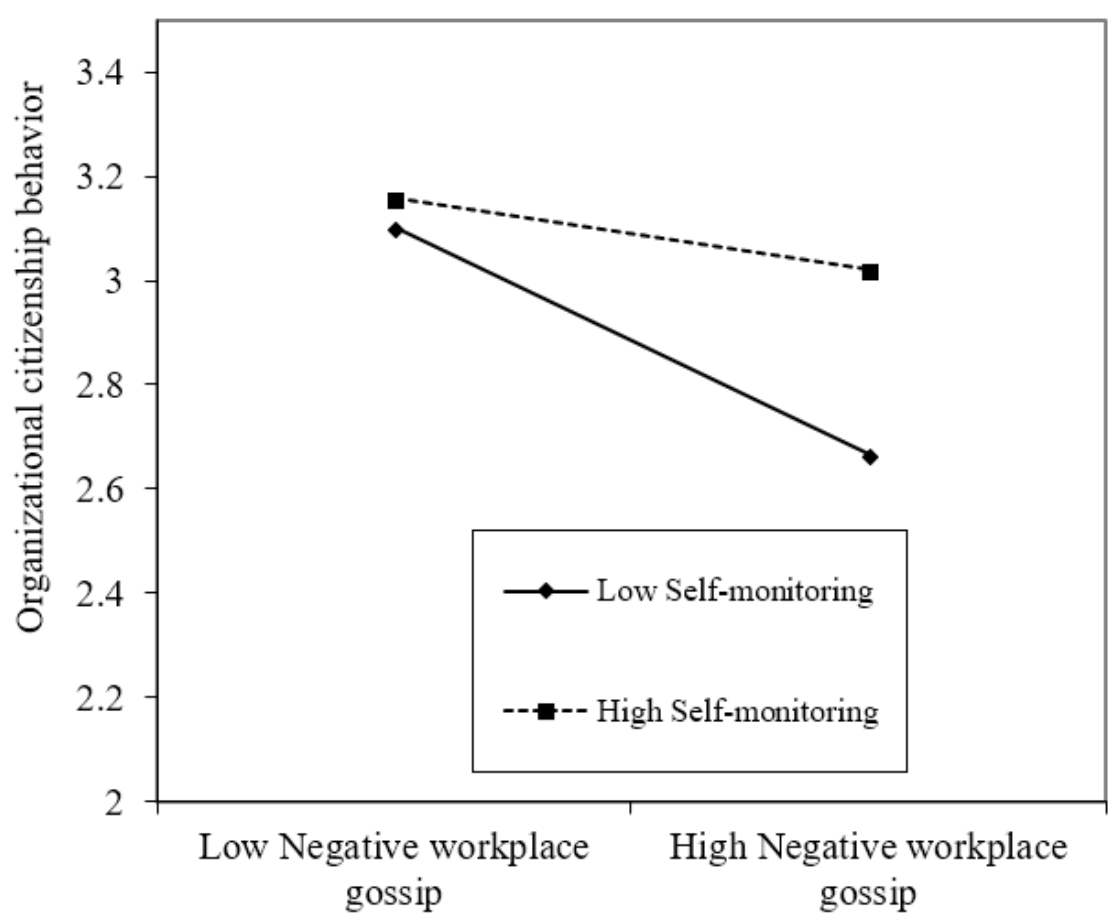

Figure 2. Moderating effect of self-monitoring on the relationship between negative workplace gossip and $\mathrm{OCB}$ 


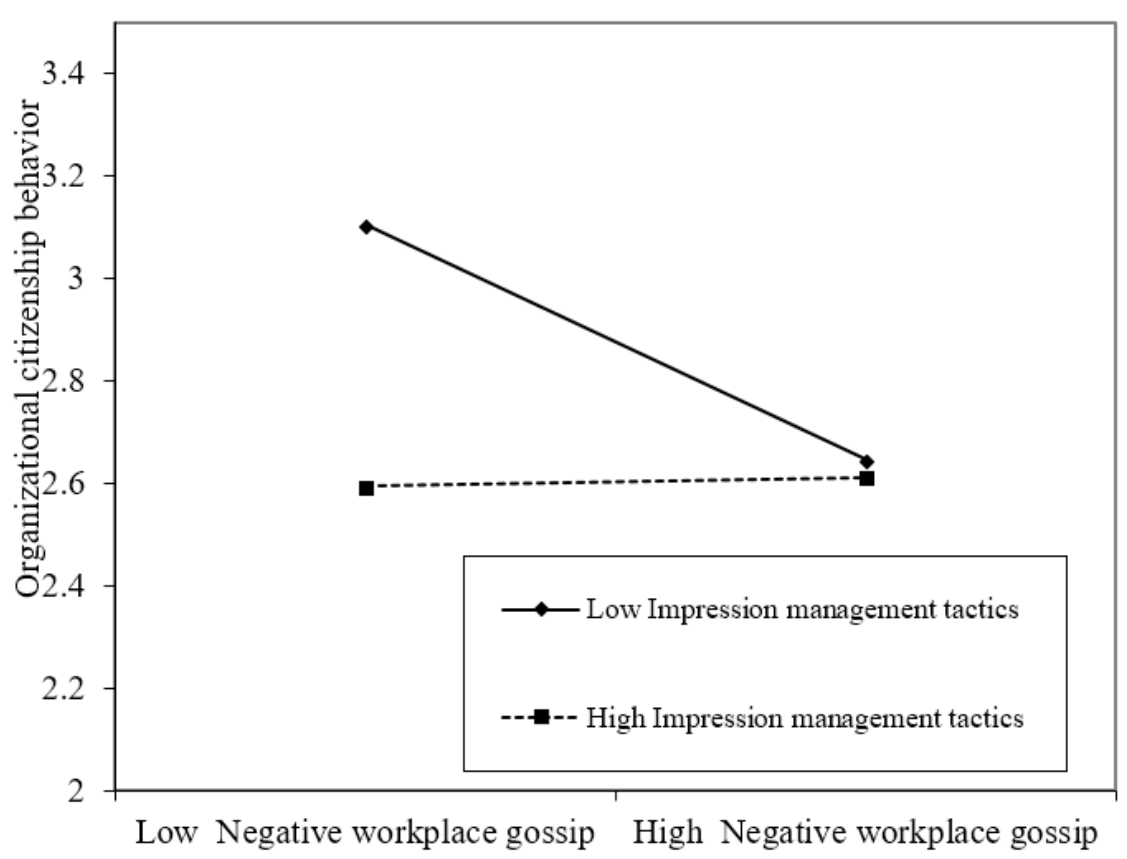

Figure 3. Moderating effect of impression management tactics on the relationship between negative workplace gossip and $\mathrm{OCB}$ 